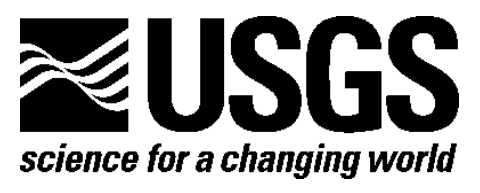

\title{
Scientific Monitoring Plan in Support of the Selected Alternative of the Glen Canyon Dam Long-Term Experimental and Management Plan
}

By Scott P. VanderKooi, Theodore A. Kennedy, David J. Topping, Paul E. Grams, David L. Ward, Helen C. Fairley, Lucas S. Bair, Joel B. Sankey, Charles B. Yackulic, and John C. Schmidt

Open-File Report 2017-1006

U.S. Department of the Interior U.S. Geological Survey 


\section{U.S. Department of the Interior \\ SALLY JEWELL, Secretary}

\section{U.S. Geological Survey \\ Suzette M. Kimball, Director}

U.S. Geological Survey, Reston, Virginia: 2017

For more information on the USGS—-the Federal source for science about the Earth, its natural and living resources, natural hazards, and the environment-visit https://www.usgs.gov/ or call 1-888-ASK-USGS (1-888-275-8747).

For an overview of USGS information products, including maps, imagery, and publications, visit https://store.usgs.gov.

Any use of trade, firm, or product names is for descriptive purposes only and does not imply endorsement by the U.S. Government.

Although this information product, for the most part, is in the public domain, it also may contain copyrighted materials as noted in the text. Permission to reproduce copyrighted items must be secured from the copyright owner.

Suggested citation:

VanderKooi, S.P., Kennedy, T.A., Topping, D.J., Grams, P.E., Ward, D.L., Fairley, H.C., Bair, L.S., Sankey, J.B., Yackulic, C.B., and Schmidt, J.C., 2017, Scientific monitoring plan in support of the selected alternative of the Glen Canyon Dam Long-Term Experimental and Management Plan: U.S. Geological Survey Open-File Report 20171006, 18 p., https://doi.org/10.3133/ofr20171006.

ISSN 2331-1258 (online) 


\section{Acknowledgments}

We would like to thank multiple people from multiple agencies for their thorough review of this document. In particular, we thank National Park Service, U.S. Bureau of Reclamation, Kirk LaGory from Argonne National Labs, and Michael Moran from the U.S. Geological Survey's Grand Canyon Monitoring and Research Center (GCMRC). This work was supported by the U.S. Bureau of Reclamation through the Glen Canyon Adaptive Management Program, with managerial support from GCMRC. 


\section{Contents}

Acknowledgments................................................................................................................................

Science Plan in Support of the Selected Alternative of the Glen Canyon Dam Long-Term Experimental

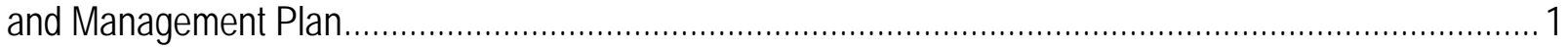

Introduction

The Study Area

Goals of the Glen Canyon Dam Adaptive Management Program............................................................. 3

Management Program for Glen Canyon Dam Operations Defined by the Selected Alternative in the

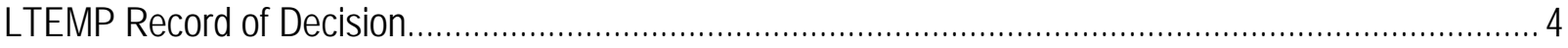

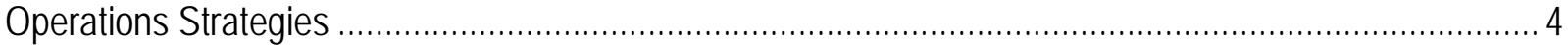

Monitoring and Research Activities in Support of the Selected Alternative of the LTEMP ROD ....................5

Monitoring Activities Specific to Implementation of Seasonal and Annual Operating Decisions for

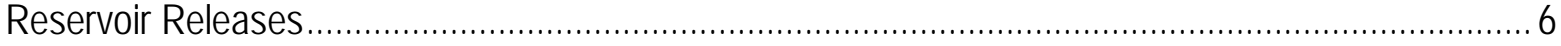

Monitoring and Research Activities to Assess the Effectiveness of Specific Experimental Management Actions Relative to Geomorphology ................................................................................. Monitoring and Research Activities to Assess the Effects of Specific Experimental Management Actions

Relative to Fish, Aquatic, and Riparian Resources

Monitoring and Research Activities to Assess the Effects of Specific Experimental Management Actions

Relative to Cultural Sites, Recreation, Hydropower, and Other Resources....................................... 11

Assessment and Reporting of Short-Term and Long-Term Effects of Dam Operations, and

Experimental Flow and Non-Flow Actions........................................................................... 13

Predictions of the Effects of Specific Experimental Management Actions on Resources........................ 14

Time Frame for Data Collection and Reporting Required to Implement the Selected Alternative of the

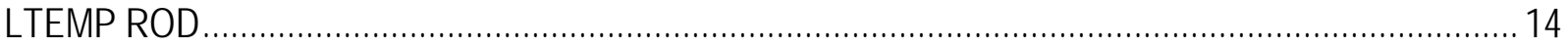

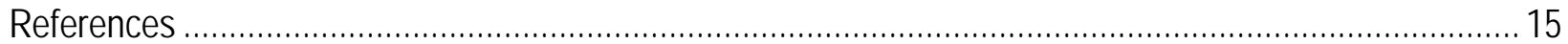




\section{Abbreviations and Acronyms}

$\begin{array}{ll}\text { AMWG } & \text { Adaptive Management Work Group } \\ \text { CRE } & \text { Colorado River ecosystem } \\ \text { DOI } & \text { U.S. Department of the Interior } \\ \text { EA } & \text { Environmental Assessment } \\ \text { FEIS } & \text { Final Environmental Impact Statement } \\ \text { ft3/s } & \text { cubic feet per second } \\ \text { FY } & \text { fiscal year } \\ \text { GCDAMP } & \text { Glen Canyon Dam Adaptive Management Program } \\ \text { GCES } & \text { Glen Canyon Environmental Studies } \\ \text { GCMRC } & \text { USGS Grand Canyon Monitoring and Research Center } \\ \text { GCNP } & \text { Grand Canyon National Park } \\ \text { GCNRA } & \text { Glen Canyon National Recreation Area } \\ \text { HFE } & \text { high-flow experiment } \\ \text { LTEMP } & \text { Glen Canyon Dam Long-Term Experimental and Management Plan } \\ \text { m3/s } & \text { cubic meters per second } \\ \text { NPS } & \text { National Park Service } \\ \text { RKM } & \text { river kilometers } \\ \text { RM } & \text { river miles } \\ \text { ROD } & \text { Record of Decision } \\ \text { RTELSS } & \text { rainbow trout early life stage study } \\ \text { TMF } & \text { trout-management flow } \\ \text { TWG } & \text { Technical Work Group } \\ \text { TWP } & \text { triennial work plans } \\ \text { USGS } & \text { U.S. Geological Survey } \\ \text { YOY } & \text { young of year }\end{array}$




\title{
Scientific Monitoring Plan in Support of the Selected Alternative of the Glen Canyon Dam Long-Term Experimental and Management Plan
}

\author{
By Scott P. VanderKooi, ${ }^{1}$ Theodore A. Kennedy, ${ }^{1}$ David J. Topping, ${ }^{1}$ Paul E. Grams, ${ }^{1}$ David L. Ward, ${ }^{1}$ Helen C.
} Fairley, ${ }^{1}$ Lucas S. Bair, ${ }^{1}$ Joel B. Sankey, ${ }^{1}$ Charles B. Yackulic, ${ }^{1}$ and John C. Schmidt ${ }^{2}$

\section{Introduction}

The purpose of this document is to describe a strategy by which monitoring and research data in the natural and social sciences will be collected, analyzed, and provided to the U.S. Department of the Interior (DOI), its bureaus, and to the Glen Canyon Dam Adaptive Management Program (GCDAMP) in support of implementation of the Glen Canyon Dam Long-Term Experimental and Management Plan (LTEMP) (U.S. Department of the Interior, 2016a). The selected alternative identified in the LTEMP Record of Decision (ROD) (U.S. Department of the Interior, 2016b) describes various data collection, analysis, modeling, and interpretation efforts to be conducted by the U.S. Geological Survey’s (USGS) Grand Canyon Monitoring and Research Center (GCMRC), partner agencies, and cooperators that will inform decisions about operations of Glen Canyon Dam and management of downstream resources between 2017 and 2037, the performance period of the LTEMP. General data collection, analysis, modeling, and interpretation activities are described in this science plan, whereas specific monitoring and research activities and detailed study plans are to be described in the GCDAMP's triennial work plans (TWPs) to be developed by the Bureau of Reclamation and GCMRC with input from partner agencies and cooperators during the LTEMP period, which are to be reviewed and recommended by the GCDAMP and approved by the Secretary of the Interior.

The GCDAMP consists of several components, the primary committee being the Adaptive Management Work Group (AMWG). This Federal advisory committee is composed of 25 agencies and stakeholder groups and is chaired by the Secretary of the Interior's designee. The AMWG makes recommendations to the Secretary of the Interior concerning operations of Glen Canyon Dam and other experimental management actions that are intended to fulfill some obligations of the Grand Canyon Protection Act of 1992. The Technical Work Group (TWG) is a subcommittee of the AMWG and provides technical advice to the AMWG. It is composed of technical and science representatives from the same agencies and stakeholder groups who serve on the AMWG. GCMRC is the primary science provider to the GCDAMP and also coordinates many aspects of the science performed by cooperators and partner agencies. The Science Advisors Program provides independent science reviews and advice at the request of the GCDAMP.

\footnotetext{
${ }^{1}$ U.S. Geological Survey.

${ }^{2}$ Department of Watershed Sciences, Quinney College of Natural Resources, Utah State University, Logan, Utah.
} 
The plan proposed here necessarily depends on (1) the protocol for decision-making and the requirements for scientific data reporting described in the LTEMP ROD, (2) the priorities of the GCDAMP as directed by the LTEMP ROD (see Department of the Interior, 2016b, section 6.1), (3) the priorities for monitoring and research in the conservation measures section of the Biological Opinion for the LTEMP (U.S. Department of the Interior, 2016b, LTEMP ROD attachment E), (4) the priorities for resource management and information needs established by Federal and State resource-management agencies within the GCDAMP, (5) scientific understanding about the linkage between the status of those resources and operations of Glen Canyon Dam, and (6) the need to resolve existing scientific uncertainties about the linkage between dam operations and the condition of resources. We note that resource-management prioritization is fundamentally a policy decision charged specifically to DOI for the Colorado River in Glen and Grand Canyons, as outlined most recently in the LTEMP ROD, and is not the responsibility of the GCMRC. However, it is the responsibility of the GCMRC to describe the nature of scientific understanding, the nature of scientific uncertainty, and the risk of making resourcemanagement decisions in the face of existing scientific uncertainty. The goals of science activities in the next 20 years are to inform operational decisions regarding Glen Canyon Dam operations described in the LTEMP ROD, resolve remaining scientific uncertainties, and to monitor resource trends that are affected entirely, or in part, by dam operations.

\section{The Study Area}

The primary research and monitoring activities of the GCMRC and its cooperators are conducted in the Colorado River ecosystem (CRE) between Glen Canyon Dam and the upstream end of Lake Mead reservoir. The approximately 25 river kilometers (RKM) or 16 river miles (RM) ${ }^{3}$ between the dam and Lees Ferry, Arizona, are in Glen Canyon and are managed by the National Park Service (NPS) as Glen Canyon National Recreation Area (GCNRA). There are 446 RKM (277 RM) between Lees Ferry and Pearce Ferry on Lake Mead. The upstream 100 km (62 miles) of this segment is physiographically defined as Marble Canyon; the downstream part is in Grand Canyon. Grand Canyon National Park (GCNP) manages these segments.

The study area includes Lake Powell, Glen Canyon Dam, and the Colorado River downstream to Pearce Ferry on Lake Mead and primarily encompasses the CRE, which includes the Colorado River mainstream corridor and interacting resources in associated riparian and terrace zones, located primarily from the forebay of Glen Canyon Dam to the western boundary of GCNP. The CRE specifically consists of the area where dam operations impact physical, biological, recreational, cultural, and other resources. This section of the river runs through Glen, Marble, and Grand Canyons in Coconino and Mohave Counties in northwestern Arizona. Although the LTEMP focuses primarily on the CRE, the affected area varies by resources and extends outside of the immediate river corridor for some resources and cumulative impacts. For resources such as socioeconomics, air quality, and hydropower, the affected region is larger and includes areas potentially affected by indirect impacts of the LTEMP.

The CRE for some of the segments identified above also include Tribal lands. Some aspects of monitoring (for example, survey markers, studies in tributaries) may require science activities to extend on to Tribal lands (with Tribal approval). Boundaries of these lands, as described in chapter 1 of the

\footnotetext{
${ }^{3}$ Locations are provided in river miles, a location system that has been used since the 1920s and indicates the distance, in miles, downstream from Lees Ferry, or the distance, in negative values, upstream from Lees Ferry.
} 
LTEMP Final Environmental Impact Statement (FEIS) (U.S. Department of the Interior, 2016a), are as follows:

The western boundary of the Navajo Indian Reservation lies near the Colorado River from Lake Powell through Glen and Marble Canyons. However, various orders and statutes reserved and withdrew land within one-quarter mile of the Colorado River to the United States for power purposes. The Kaibab Paiute Indian Reservation is on the plateau north of GCNP. The Havasupai Indian Reservation surrounds upper Havasu Creek, immediately south of GCNP. The Hualapai Indian Reservation comprises the southern portion of western Grand Canyon, adjacent to GCNP.

Although the focus of GCMRC activities and those of its cooperators funded by the GCDAMP is explicitly on the study area, scientific insights that potentially inform management decisions come from a wider range of localities. GCMRC and its cooperators will evaluate and refer to the full range of relevant scientific information available to them as necessary. The natural stream-flow regime of the Colorado River in the study area has been changed such that flood flows are smaller, base flows are larger, and daily fluctuations occur as a result of operations to generate hydroelectric power (Topping and others, 2003). Typically, water releases from Lake Powell reservoir have stable thermal regimes with warmer winter temperatures, colder summer temperatures, and an overall narrow annual range of temperatures (Vernieu and others, 2005). Trapping of the incoming sediment load produced in the Upper Colorado River basin is inevitable in a reservoir as large as Lake Powell. Thus, downstream sediment transport is much less than in pre-dam times. The combination of changes in stream-flow regime and sediment trapping leads to perturbation of the river's sediment mass-balance equilibrium and shifts the river towards geomorphic processes that tend to evacuate fine sediment (Topping and others, 2000a, Topping and others, 2000b, Rubin and others, 2002, Topping and others, 2003). Ecological processes have also been affected by these geomorphic changes. Decreased sediment loads and resulting increased water clarity have shifted the aquatic food base from one based primarily on terrestrial (that is, allochthonous) inputs to one that largely derives energy from aquatic primary producers (that is, autochthonous) such as algae and diatoms (Kennedy and Gloss, 2005). Clear water with colder average temperatures and narrower annual temperature ranges has favored introduced coldwater fishes like rainbow trout (Oncorhynchus mykiss) over warm-water native species like humpback chub (Gila cypha) (Coggins and Gloss, 2005). Reductions in the magnitude of flood flows and increases in the magnitude of baseflows has resulted in less area available to riparian adapted species, while simultaneously promoting increases in the amount and density of riparian vegetation in this zone (Sankey and others, 2015). Dam-induced changes to the river's hydrology have also promoted encroachment of native and nonnative upland vegetation into riparian areas.

\section{Goals of the Glen Canyon Dam Adaptive Management Program}

The CRE is a complex suite of physical, chemical, and biological attributes and processes. Some ecosystem attributes are valued by humans and these attributes are typically referred to as "resources." Although some resources are solely valued because they are part of the natural environment, other resources have archeological, cultural, recreational or other societal values (for example, hydroelectricity). Some attributes of the natural environment, such as wildlife and fish populations, are intrinsically valued in their own right. Other attributes have intrinsic value but are also important for their linkages to resources; for example, bare sandbars provide campsites, help preserve archeological sites, and can provide habitat for native species. Ecosystem resources are maintained by ecosystem processes such as sediment transport, evapotranspiration, and interspecific competition, but their status and value is also subject to human activities and perceptions. 
The target resources of the GCDAMP have changed with time. In 1988, for example, Glen Canyon Environmental Studies (GCES) identified seven "critical resources” that primarily concern biology and recreation-humpback chub, common native fish, rainbow trout, camping beaches, riparian vegetation and wildlife, whitewater boating, and trout fishing (Bureau of Reclamation and others, 1989, p. 17). The underlying physical and biological attributes and processes that create and maintain these critical resources were recognized, and as a result, GCES research focused on sediment transport, hydrology, terrestrial biology, aquatic biology, and dam operations. The GCMRC's 1997 Strategic Plan defined nine resources - water, sediment transport, fishes, vegetation, wildlife and wildlife habitat, endangered and other special status species, cultural resources, recreation, and hydropower. Schmidt and others (1998) distinguished these resources as either relicts of the pre-dam river ecosystem or artifacts of the post-dam river ecosystem. Another example is the GCDAMP's 2012 desired future conditions (U.S. Department of the Interior, 2012) that were described in four categories - ecosystem, power, cultural resources, and recreation.

Going forward, the LTEMP ROD indicates that the goals of the GCDAMP will be the goals and objectives identified within the LTEMP FEIS in section 1.4 and in the LTEMP ROD. However, the LTEMP ROD also notes that there will be a need to develop more specific monitoring metrics for these goals (see U.S. Department of the Interior, 2016b, section 6.1c).

\section{Management Program for Glen Canyon Dam Operations Defined by the Selected Alternative in the LTEMP Record of Decision}

Implementation of the LTEMP ROD and management of Glen Canyon Dam operations will require close cooperation and coordination among decision-makers, resource managers, stakeholders, and scientists. Information regarding the status and responses of resources of interest must be provided at a range of time intervals (that is, monthly, biannually, yearly, decadal) to inform the decision-making process that also operates on many different time scales. These decisions concern implementation or suspension of experiments, experimental management actions involving other aspects of dam operations, or experimental management actions that do not involve dam operations. Key resources specifically identified in the LTEMP ROD include (1) water quality and water delivery, (2) humpback chub, (3) sediment, (4) riparian ecosystems, (5) historic properties and traditional cultural properties, (6) Tribal concerns, (7) hydropower production and the Upper Colorado River Basin Fund (see https://www.usbr.gov/uc/rm/crsp/bf.html), (8) the rainbow trout fishery, (9) recreation, and (10) other resources. In addition, the ROD states that there will be flexibility in the implementation of experiments by DOI to allow appropriate responses to any unexpected events that involve resources not listed above.

The broad scope of these resources necessitates information input from a variety of sources such that managers are fully informed before making decisions concerning high flow experiments (HFEs), actions to manage trout populations, or other activities identified in the LTEMP ROD. GCMRC and its cooperators are the primary providers of information on physical resources such as water quality and sediment and biological resources such as native and nonnative fishes, the aquatic food base, and riparian ecosystems. GCMRC and its cooperators will also be able to provide some of the needed information on cultural and socioeconomic aspects of some resources, including historic and traditional cultural properties, hydropower, and recreation. Additional information on these and other resources will need to be provided by other entities including Tribes, Federal and State agencies, and stakeholders.

\section{Operations Strategies}

Most of the dam operations strategies (referred to as "condition-dependent and experimental elements”) identified in the LTEMP ROD are focused on management of sediment-dependent 
resources. These strategies include (1) HFEs in the fall whose duration is 96 hours or less, (2) extendedduration HFEs in the fall that might last as long as 250 hours, (3) HFEs in the spring whose duration is 96 hours or less, and (4) HFEs of as long as 24 hours in the spring that would occur in water years when 10 million acre feet or more of water is released from Lake Powell. In aggregate, implementation of these strategies is intended to increase the size and abundance of eddy sandbars throughout the study area, especially in upper and lower Marble Canyon. In all cases, the maximum magnitude of HFEs is to be 45,000 cubic feet per second $\left(\mathrm{ft}^{3} / \mathrm{s}\right)\left(1,274\right.$ cubic meters per second, $\left.\mathrm{m}^{3} / \mathrm{s}\right)$.

Three other operations strategies are included in the selected alternative that target aspects of the aquatic ecosystem. These strategies include (1) low summer flows, (2) macroinvertebrate production flows, and (3) trout management flows (TMFs). Aquatic-ecosystem-focused operations strategies are designed to benefit humpback chub either directly or indirectly. Low summer flows, which may only occur in the second 10 years of the LTEMP period, are intended to warm river temperatures such that growth rates of young humpback chub increase, allowing these fish to quickly grow through vulnerable size classes and ultimately increasing recruitment into the adult population. Macroinvertebrate production flows would consist of low steady flows on weekend days between May 1 and August 31 to mitigate a hypothesized recruitment limitation of some aquatic insects. Mortality of insect eggs laid along the river shoreline may be unnaturally high because fluctuating flows associated with hydroelectric operations result in a relatively large varial zone (Kennedy and others, 2016). Proposed low summer flows and macroinvertebrate production flows could benefit humpback chub directly and indirectly. Direct benefits to humpback chub would occur if aquatic food base productivity and diversity increase due to reductions in flow fluctuations on weekends, thereby providing more and higher quality food resources. Warmer temperatures associated with low summer flows could also lead to increased growth rates allowing young humpback chub to grow quickly beyond sizes at which they are most vulnerable to predators. Indirect benefits would occur if rainbow trout resident in Glen Canyon benefit from these same operational changes and thus become less likely to emigrate downstream into Marble Canyon, where they might compete with or prey on humpback chub (Yard and others, 2011). Trout management flows are also intended to reduce downstream movement of trout by reducing the density of rainbow trout in Glen Canyon by creating a flow regime that strands young-of-year (YOY) fish (those fish produced in one reproductive year).

We also note that these operations strategies may have negative consequences. Low summer flows and macroinvertebrate production flows could create conditions that benefit unwanted nonnative fishes, which in turn could harm humpback chub through competition or predation. Direct harm to humpback chub, razorback sucker (Xyrauchen texanus), and other native fishes could also occur due to stranding caused by TMFs. Finally, these operations strategies may affect the study area's fine sediment mass balance or the distribution of fine-sediment deposits.

\section{Monitoring and Research Activities in Support of the Selected Alternative of the LTEMP ROD}

A number of monitoring and research activities are important for the implementation of the LTEMP ROD and its successful execution during the next 20 years. Decisions about initiating, continuing, or ending specific experimental management actions or operations identified in the ROD are dependent on the status of key resources and the results of experiments. Here we provide an overview of activities that GCMRC proposes to conduct to provide the necessary information to decision-makers regarding decisions to initiate an experimental management action (hereafter referred to as "triggers”), decisions to abandon a particular course of action (hereafter referred to as "off ramps"), and evaluations of the effectiveness of experiments and actions conducted during the period of performance of the 
LTEMP. The implementation of the LTEMP will occur in an adaptive management framework, thus science activities described here may be modified in response to learning, changing environmental conditions, or other unforeseen circumstances.

\section{Monitoring Activities Specific to Implementation of Seasonal and Annual Operating Decisions for Reservoir Releases}

Implementation of each experimental element of the selected alternative is to be triggered by specific ecosystem conditions, and the decision not to implement any of these elements is to be based on assessment of other ecosystem resource conditions. Specifically, fall HFEs, extended-duration HFEs, and spring HFEs are all to be triggered by sufficient Paria River sediment input. Proactive spring HFEs are to be triggered by planned equalization reservoir releases of 10 million acre feet or more of water.

In all cases, these experimental actions can temporarily be suspended or permanently abandoned if specific resource conditions so dictate, as specified by the LTEMP ROD. The off-ramps for normal duration HFEs are that these controlled floods are not effective in building sandbars or have long-term unacceptable adverse impacts on the key resources listed in the ROD. Thus, timely data collection, analyses, and reporting of fine sediment inputs and of the status of key ecosystem resources (for example, humpback chub, nonnative fishes) are fundamental parts of implementation of these experimental elements of the LTEMP.

Spring or fall HFEs are to be triggered by sufficient inputs of sand from the Paria River. The implementation program for these "sediment triggered" HFEs is described in appendix C of the LTEMP ROD and is unchanged from the HFE protocol Environmental Assessment (EA) (Bureau of Reclamation, 2011a), which established the experimental protocols to manage limited sediment resources in Marble and Grand Canyons with repeated HFEs (as many as two per year) as conditions warranted. The measurement strategy to define these triggers involves the continuous measurement of the river stage of the Paria River to estimate the hydrograph of each flood event, automated and field collection of suspended sediment samples of the flooding Paria River, laboratory analyses of those samples to determine the concentration and grain sizes of suspended sediment, and application of a model that predicts total sediment transport of clay, silt, and sand during each flood. These data are used to estimate the total amount of sand delivered to the Colorado River during each "sediment accounting season.” These data are then compared with similar data collected by acoustic sensors, automated samplers, field samples, laboratory analyses, and sensor calibration data for Colorado River gaging stations. The mass balance of sand in different parts of Marble and Grand Canyons is determined and reported to Bureau of Reclamation engineers who subsequently estimate sand transport during controlled floods of different potential duration and magnitude using numerical models. Implementation of the protocol is described by Grams and others (2015), and all data used in this protocol are accessible to the public at GCMRC’s Web site (https://www.gcmrc.gov).

All activities needed to implement spring and fall HFEs in terms of estimates of fine sediment inputs, transport, and mass balance are included in the current TWP (fiscal years (FY) 2015-17) (Bureau of Reclamation and U.S. Geological Survey, 2014). Subsequent TWPs will be developed for following 3-year periods. GCMRC intends to continue implementing its program of measuring finesediment delivery from major and minor tributaries, transport by the Colorado River, delivery of that fine sediment to Lake Mead, and computation of the fine-sediment mass balance of various segments of the Colorado River in the study area in future TWPs, such that information needs identified in the LTEMP ROD are met. The fine-sediment monitoring program described above is considered to be adequate to support decision-making about implementation of all proposed HFEs (fall, extendedduration fall, spring, proactive spring), because the data needed for decision-making are no different than the data needed for implementation of the HFE protocol (Bureau of Reclamation, 2011a). It is 
recognized that new technologies for the measurement and estimation of fine-sediment inflows to the Colorado River may be developed during the 20-year duration of the LTEMP, and GCMRC expects to incorporate new technological and analytical advances into its future monitoring program.

\section{Monitoring and Research Activities to Assess the Effectiveness of Specific Experimental Management Actions Relative to Geomorphology}

Applied-science monitoring activities are partly focused on informing decisions about those dam operations intended to maintain and (or) increase the size of sandbars throughout Marble and Grand Canyons. These bars typically occur in eddies downstream from rapids and are used as campsites by river runners and serve as sources of wind-blown sand found at higher elevations throughout the CRE. Eddy sandbars occur more frequently where the Colorado River is relatively wide, such as in lower Marble Canyon, and less frequently where the Colorado River is relatively narrow, such as in Upper Granite Gorge (Schmidt and Graf 1990). Thus, monitoring of sandbar characteristics must distinguish among the different river segments of Marble and Grand Canyon (Schmidt and Graf 1990), because the average sandbar characteristics for the entire study area typically differ from the features of sandbars in shorter segments.

Another aspect of implementation of the various experimental elements identified in the ROD is the regular assessment of their effectiveness. The commitment to provide data relevant to the evaluation of each experiment and any effects on resources of interest is made in the ROD in the following statements (U.S. Department of the Interior, 2016b, LTEMP ROD attachment B):

- "For these experiments, effectiveness will be monitored and the experiments will be terminated or modified only if sufficient evidence suggested the treatment was ineffective or had unacceptable adverse impacts on other resources."

- "All experimental treatments will be closely monitored for adverse side effects on important resources.”

Ongoing monitoring of sandbars by GCMRC and its cooperators includes annual topographic monitoring of some sandbars, daily photography of other sandbars, and experimental evaluation of alternative technologies for measuring sandbar topography. Another aspect of this work is the development of an integrated monitoring protocol that explicitly defines uncertainty associated with generalizations about the average characteristics of sandbars in different parts of the study area. GCMRC intends to continue to propose these types of monitoring activities in future TWPs, although the mix of various spatial and temporal scales of effort is expected to change. GCMRC also intends to propose strategies for serving all these data on its Web site in an ongoing way to stakeholders.

Some experiments must be monitored and their effects compared with the effects of other actions. For example, extended-duration fall HFEs would not be continued if it is determined that they are not effective in building sandbars or that resulting sandbars are no bigger than those created by shorter-duration HFEs. Proactive spring HFEs would not be continued if they are not effective in building and maintaining sandbars. To make such determinations, criteria or standards will need to be developed by GCMRC in collaboration with the GCDAMP regarding how effectiveness in this context is to be determined. The ROD also provides an off-ramp from TMFs if there are "unacceptable adverse impacts on ... other resources.” Depending on their final configuration, the magnitude and timing of daily fluctuations during TMFs may be such that there is the potential for accelerated sandbar erosion caused by these flows (Alvarez and Schmeeckle, 2013). Thus, the potential effects of TMFs on sandbar erosion must be evaluated and subsequently monitored if the risk of erosion appears greater than that of routine operations.

These assessments provide a challenge to GCMRC science, because measurements and predictions of the effectiveness of dam operations potentially require measurements of a number of river 
processes. Examples include temporal changes in suspended-sediment concentration during floods, longitudinal changes in suspended-sediment concentration in different parts of the study area, lateral changes in concentration in eddy deposition zones, comparison of the topography of sandbars on different days of a controlled flood to determine day-to-day changes in the deposition rate of fine sediment in eddies, and comparison of the topography of sandbars in different parts of the study area. Studies to better understand these processes were conducted during the 1996 controlled flood (Webb and others, 1999) and during some other controlled floods (Melis, 2011) but have not been conducted since the HFE protocol was implemented in 2012 due to the considerable effort and expense required. GCMRC believes it important to conduct studies that synoptically consider changes in sediment transport, eddy sandbar deposition, or eddy sandbar erosion to determine the effectiveness of long-term and proactive HFEs. Given the expense of these studies and uncertainty as to when these types of HFEs may be triggered, development of a contingency fund may be warranted to ensure adequate funding is available for implementation. Such a fund would support synoptic measurement programs during and after any extended-duration fall HFE or proactive spring HFE to evaluate whether or not significant sandbar deposition occurred relative to the results of recent 96-hour HFEs conducted under the HFE Protocol.

GCMRC commits to proposing a formal program for monitoring and analysis of the specific experiments of the LTEMP in the next TWP. Approaches may include expansion of the structure-frommotion approach being tested by GCMRC in the current TWP or lidar (light detection and ranging) topographic measurement programs as strategies to quickly collect field topographic data that will be useful in the analysis of rates of post-flood erosion needed to evaluate the effectiveness of all types of HFEs.

Assessment of long-term trends in sandbar size and other geomorphic attributes of the Colorado River, such as alluvial terraces in Glen Canyon, is also needed. The ROD establishes a decision point 10 years after its implementation to continue operations or trigger alternative actions that are dependent on this information. Decadal-scale trends in sandbar size will be evaluated by analysis of the annual sandbar monitoring data (described previously). Additional information could be provided by analysis of images collected by periodic (every 4 to 10 years) remote-sensing missions. Collection and analysis of annual sandbar monitoring data and analysis of existing remote-sensing data are included in the current TWP. The collection and analysis of annual sandbar monitoring data, as well as the timing and scope of potential future remote-sensing missions, are to be addressed in the planning and development of future TWPs.

The sandbars exposed along the channel margins that are the focus of many experimental actions identified in the LTEMP ROD constitute only a fraction of the total sand storage in Marble and Grand Canyons (Grams and others, 2013). Consequently, changes in the size and abundance of emergent sandbars is not precisely correlated with overall sand storage (Hazel and others, 2010). Decadal-scale changes in total sand storage of long segments of the Colorado River may be determined by analysis of the mass-balance sand budgets computed from the continuous measurements of sand flux used for HFE planning. However, uncertainty in these measurements accumulates such that changes in sand storage over years to decades may be indeterminate. Alternatively, analysis of repeat maps of the riverbed in long river segments may also be used to monitor sand storage. This approach reveals the magnitude of changes in sand storage, as well as where those changes occur with levels of uncertainty that are appropriate for long-term monitoring (Grams and others, 2015). This method has been used to document the magnitude and pattern of sand evacuation that occurred in lower Marble Canyon during the 2011 reservoir equalization flows (Grams and others, 2015). In addition, baseline maps of the riverbed have been collected for all river segments between Glen Canyon Dam and RKM 140 (RM 87). By the end of FY 2017, baseline data will be collected for the segment between RKM 267 and 362 (RM 166 and 225). 
Collection of data for the segment between RKM 140 (RM 87) and RKM 267 (RM 166) will be proposed in the FY 2018-20 TWP. In addition, GCMRC proposes to convene a panel of independent experts to evaluate this and other methods employed by the program to monitor sandbar dynamics, erosion, changes in sand mass balance, and other geomorphic features and processes that may be affected by experiments implemented as part of the ROD. Analysis of repeat maps based on data collected between 2015 and 2020 will be used to evaluate changes in the magnitude and spatial distribution of total sand storage and inform the decision to continue or alter operations in the future.

\section{Monitoring and Research Activities to Assess the Effects of Specific Experimental Management Actions Relative to Fish, Aquatic, and Riparian Resources}

The implementation and continuation of all of the proposed experiments and actions identified in the ROD are contingent on the responses of one or more biological resources. These responses are identified as conditions in triggers, decision points, and off-ramps (see U.S. Department of the Interior, 2016b, LTEMP ROD attachment B, table 4 and figure 5) and primarily focus on humpback chub and rainbow trout. These responses include specific conditions such as "no increase in growth and recruitment of humpback chub" and "little or no effect on trout recruitment." Another condition concerns trout recruitment affected by some treatments, as well as the more generic conditions such as unacceptable adverse impacts on the rainbow trout fishery, humpback chub population, or other resources. Other resources that could trigger or suspend actions if responses or changes were observed, include appearance of or increases in abundance of warm-water nonnative fishes or undesired changes in the characteristics of the aquatic food base or riparian-vegetation community. Conditions for these resources include increases in warm-water nonnative fishes near the Little Colorado River, "little or no benefit on food base," and, for riparian vegetation, "control and replanting techniques are not effective or practical."

Monitoring of native and nonnative fishes will need to be able to provide information on a number of parameters that may include distribution, relative abundance, and vital rates like growth, survival, and recruitment. Multiple life-history stages of humpback chub will need to be monitored in support of the LTEMP ROD. The abundance of subadult and adult humpback chub in the segment of the Colorado River that includes the confluence of the Little Colorado River (RKM 91-106; RM 57-66) and the Little Colorado River downstream from Blue Spring will need to be estimated on an annual basis. Specific trigger levels for subadult and adult abundance were identified by the U.S. Fish and Wildlife Service in its Biological Opinion for the LTEMP FEIS (U.S. Department of the Interior, 2016b, LTEMP ROD attachment E). Growth and recruitment rates of YOY humpback chub will also need to be monitored. Growth-rate data would be needed to test the effectiveness of low summer-flow experiments to be conducted only in the second 10 years of the LTEMP period. It will be important to have baseline data from the first 10 years to determine long-term trends. These data could also be used to improve understanding of the relation between growth rates of YOY humpback chub and subsequent recruitment into the subadult or adult life stages.

Monitoring of rainbow trout may need to occur at several locations and include multiple lifehistory stages. Given the need to understand the effects of HFEs, TMFs, and other experimental flows on the population dynamics of rainbow trout and other species of interest, the monitoring approach must be sufficiently robust to detect changes in distribution, reproduction, survival, recruitment, and growth. The recent increase in brown trout (Salmo trutta) catch in Glen Canyon (Winters and others, 2016) also demonstrates the need for flexibility such that monitoring activities can be modified in a timely manner to address emerging issues.

The Colorado River segment in Glen Canyon (RKM -25-0; RM -16-0) and the segment immediately downstream from the Little Colorado River confluence (RKM 102-105; RM 63.5-65.2) 
are of interest. Glen Canyon is the segment including most of the spawning habitat for rainbow trout and has the highest densities of this species downstream from Glen Canyon Dam. Glen Canyon is also the location of the rainbow trout recreational sport fishery and where brown trout spawning and rearing has recently been observed. Monitoring of rainbow trout and brown trout in this segment may need to include a measure of reproduction levels; estimates of abundance, survival, growth, and distribution of YOY trout; and estimates of abundance, growth, and condition of yearling to adult fish. Trends in catches of trout by recreational fishers and the quality of the sport fishery may also be monitored. The segment downstream of the Little Colorado River has the highest densities of young humpback chub in the main stem and is the segment with the highest risk for predation and competition from rainbow trout and brown trout. Given this, the abundance, size-class distribution, and residence time of rainbow trout and brown trout in this segment is to be monitored. In addition, other Colorado River segments and tributaries that support rainbow trout or brown trout spawning and rearing (for example, Marble Canyon, Bright Angel Creek) may be monitored as needed to understand what role these areas play as sources of trout to critical segments such as near the Little Colorado River.

Should mechanical removal of trout be triggered, monitoring will occur to determine if this experimental management action is effective in reducing trout densities and maintaining these densities at low levels. Mechanical removal of trout, and any associated monitoring, will occur in segments immediately upstream and downstream from the Little Colorado River confluence (potentially from RKM 80-106; RM 50-66). In recognition of Tribal concerns regarding the taking of life in the Canyon, beneficial uses would be found to the extent practicable for fish harvested during any mechanical removal effort. Approaches for the beneficial use of harvested fish similar to those employed by GCNP for trout removal in and near Bright Angel Creek will be used (National Park Service, 2013).

Nonnative fishes, particularly warm-water and piscivorous species, pose a direct and real threat to humpback chub and other Colorado River native fishes (Minckley, 1991). Monitoring will occur to detect the appearance of previously absent species or the expansion in abundance, distribution, or spawning of extant nonnative fishes. Monitoring will occur in the entire Colorado River from Glen Canyon Dam to Lake Mead and will be conducted in collaboration with other agencies' efforts funded outside the GCDAMP. Glen Canyon and the segment just upstream from Lake Mead will be monitored closely because of their proximity to known sources of warm-water nonnative fishes. In addition, the lower Little Colorado River and the Colorado River near the Little Colorado River confluence will be monitored carefully because the upper segments of the Little Colorado River are known sources of warm-water nonnative fishes, and these areas have the highest densities of all life stages of humpback chub in Grand Canyon (Valdez and Ryel, 1995).

Monitoring of fisheries resources as described in the TWP for FY 2015-17 may provide much, but not all, of the information related to humpback chub, rainbow trout, brown trout, and warm-water nonnative fishes required for implementation of the LTEMP. Meeting all of the information needs necessary to implement the actions of the selected alternative in the ROD will require revisions in the timing and frequency of some sampling efforts, as well as the addition of monitoring not described in the TWP. For example, data on rainbow trout early life stages will be essential for evaluating the effectiveness of TMFs. However, the current design for the rainbow trout early life stage study (RTELSS) as described in the FY 2015-17 TWP is likely inadequate and requires revision to provide the necessary data to determine if TMFs can be an effective means of controlling trout recruitment. The planned ends of juvenile chub monitoring and natal origins of rainbow trout studies in FY 2017 leave large gaps in the sources of key pieces of information on humpback chub and rainbow trout needed to support LTEMP implementation. These and other topics were included in the review of the GCDAMP fisheries program conducted in August 2016 by a panel of experts external to the program (Bureau of Reclamation and U.S. Geological Survey, 2014). Recommendations from this protocol evaluation panel 
will inform GCMRC, cooperators, and partner agencies regarding best practices and methods as well as appropriate levels of effort required for future monitoring of humpback chub, rainbow trout, brown trout, and other native and nonnative fishes of interest in Glen and Grand Canyons. In future TWPs, GCMRC intends to continue to monitor the population dynamics, distribution, movements, growth and other relevant information regarding key species like humpback chub and rainbow trout. We also intend to add or modify current monitoring of emerging species of interest like brown trout and green sunfish (Lepomis cyanellus) in the various segments of the Colorado River and important tributaries in the study area such that information needs in the LTEMP ROD are met.

The aquatic food base will need to be monitored to determine if experimental treatments lead to increased productivity of the existing prey base of midges and blackflies. In addition, monitoring will be needed to determine if increases in the diversity of the prey base, such as colonization of the mainstem by orders Ephemeroptera (mayflies), Plecoptera (stoneflies), and Trichoptera (caddisflies), collectively referred to as EPT, have occurred. Monitoring of key life-stages of aquatic insects, particularly larvae and adults, will be needed, as will sampling over a broad geographic range. Focused studies of egglaying locations of aquatic insects and egg mortality will be conducted at selected sites. Data on the species composition and distribution of adult insects and timing of emergence is needed for the entire river corridor between Glen Canyon Dam and Lake Mead and will be collected as part of an ongoing project. These efforts, described in the TWP for FY 2015-17, will provide the information required for implementation of the LTEMP and will be included in future TWPs. Continued monitoring of invertebrate drift in Lees Ferry and Marble Canyon may also be included in future TWPs to improve the understanding of how experimental operations affect drivers of rainbow trout growth, survival, and movement. This information could also be used to help determine how these effects cascade upwards through trophic interactions to affect wildlife (for example, bird, bat, reptile) populations. Likewise, continuation of low-cost approaches for monitoring algae production involving development of dissolved oxygen budgets that are currently being conducted in collaboration with GCMRC's waterquality monitoring program may also be proposed, because these data may help explain trends in invertebrate and fish populations.

Experimental non-flow riparian vegetation treatments will be performed under the LTEMP, and will include nonnative plant removal, establishing sources of native plants, native-species plantings, controlling vegetation encroachment at campsites, increasing aeolian transport between sandbars and dune fields through vegetation management, and helping protect cultural sites through vegetation management. NPS will lead these efforts in cooperation with Tribes and GCMRC. Because these activities would occur at specific locations that have not yet been identified, specifics about monitoring these actions, including the scope, intensity, and duration, will necessarily need to be determined once proposals for specific actions are developed. Once the scope, and therefore costs, of specific treatments is better defined, development of a contingency fund may be warranted to ensure adequate funding is available for implementation.

\section{Monitoring and Research Activities to Assess the Effects of Specific Experimental Management Actions Relative to Cultural Sites, Recreation, Hydropower, and Other Resources}

In addition to the resources discussed above, other resources of interest specifically identified in the LTEMP ROD include historic and traditional cultural properties, Tribal concerns, hydropower production and the Upper Colorado River Basin Fund, and recreation. As noted previously, GCMRC and its cooperators can help provide scientific information on the effects of experimental elements identified in the LTEMP ROD on cultural and socioeconomic resources. However, these efforts will require cooperation and collaboration with Tribes, Federal and State agencies, and non-Federal stakeholders who may have relevant information concerning these and other resources. 
Although no specific experimental treatments for historic or traditional cultural property preservation are identified in the ROD, it does include experimental HFEs designed to build and retain sandbars and non-flow actions intended to manage vegetation in relation to cultural sites. Continued research to determine the degree to which aeolian transport of HFE-derived sand affects archeological sites, as described in the current TWP, will provide quantitative measurements of one of the potential effects of flow actions on historic and traditional cultural properties in GCNRA and GCNP. GCMRC proposes to continue measuring changes in archeological sites due to aeolian transport of HFE-derived sand, gullying and bank slumping, or other factors in the study area in future TWPs. GCMRC also proposes to evaluate how non-flow actions, such as targeted vegetation removal, can affect archeological sites. Other projects from the current TWP, such as quantifying changes in the distribution and abundance of culturally important plants, may be proposed in future TWPs pending the outcome of ongoing work.

The implementation and continuation of all proposed experiments and actions identified in the ROD are contingent on the responses of one or more socioeconomic metrics. These metrics include specific conditions such as "unacceptable impacts to" resources of Tribal importance, hydropower production, and the Upper Colorado River Basin Fund or recreational interests in annual implementation decisions, as well as the consideration of Tribal concerns regarding actions if successful (see U.S. Department of the Interior, 2016b, LTEMP ROD attachment B, table 4). Discussions with Tribes will be needed to determine when resource conditions are unacceptable to them. Monitoring and research of socioeconomic impacts, in support of the LTEMP ROD and any coordination with the Tribes that may occur, will be able to provide general information on a number of parameters. These may include, but are not limited to, Tribal preferences for resource attributes and economic values, as well as recreational preferences, regional expenditures, and economic values related to resource impacts from sedimentresource and aquatic-resource treatments.

Monitoring and research of Tribal perspectives may need to occur for individual Tribes on a periodic basis. Tribes may have specific culturally determined perspectives that change over time as the state of resources downstream from Glen Canyon Dam change and as experimental sediment-resource and aquatic-resource treatments are implemented adaptively as part of the LTEMP ROD. Any GCMRC research on Tribal perspectives will need to be conducted in close coordination with each Tribe involved.

Monitoring of recreation will include angling, whitewater boating, and potentially other recreational groups on a periodic basis. Given the need to understand the effects of HFEs, TMFs, and other experimental flows on angling in GCNRA and whitewater boating in GCNP, the monitoring approach must be sufficiently robust to detect changes in preferences, regional expenditures, and economic values associated with each recreational activity. The primary Colorado River segments of interest are in Glen Canyon (RKM -25-0; RM -16-0), the location of the recreational sport fishery, and Marble and Grand Canyons (RKM 0-445; RM 0-277), where whitewater boating occurs.

Meeting all of the LTEMP information needs regarding socioeconomic resources may require a continuation of current recreation and Tribal related monitoring and research. Additional monitoring and research of socioeconomic resources may also be needed. For example, as resource conditions and recreational and Tribal preferences for resource attributes change, periodic surveys, building on past work, would be needed to evaluate and address recreational impacts and Tribal concerns related to experimental treatments. A GCMRC study from its FY 2015-17 TWP titled "Economic Values of Recreational Resources along the Colorado River-Grand Canyon Whitewater Floater and Glen Canyon Angler Values” provides new baseline information and identifies additional information needs related to recreational preferences, regional expenditures and economic values. In addition, because implementation of a GCMRC study titled "Tribal Perspectives for and Values of Resources 
Downstream of Glen Canyon Dam” is only beginning in FY 2017, these research activities will need to be included in the FY 2018-20 TWP if the study is to be completed. GCMRC may propose additional projects in future TWPs to continue its program of monitoring and research of recreational preferences, regional expenditures, economic values, and Tribal perspectives (preferences for resource attributes and economic values) of resources in various segments of the Colorado River and key tributaries in the study area such that information needs of the LTEMP are met.

\section{Assessment and Reporting of Short-Term and Long-Term Effects of Dam Operations, and Experimental Flow and Non-Flow Actions}

Although HFEs and other experiments may occur more than once per year, it is not possible for GCMRC and its cooperators to provide any sort of formal reporting on resource condition more frequently than once per year due to the substantial potential reporting expectations in the LTEMP. For example, an off-ramp to each experimental action is based on either (1) a lack of desired resource response or (2) long-term unacceptable adverse impacts on resources. In addition, different experimental actions might occur once or twice in any year. The large number of resources of interest and variety of potential actions, plus the need for substantial time to collect, analyze, and interpret data, in any given year preclude GCMRC from evaluating the responses and condition of all resources of interest or from providing a formal reporting for each action on less than an annual basis. To keep managers and stakeholders informed, GCMRC instead plans to establish a Web-based "living document” on its homepage — similar in structure to data presently served on GCMRC's maps and data portal concerning stream flow, sediment transport, water quality, and sandbar characteristics - where status of resource data are available for review by the public. These provisional data will, at a minimum, include time series of changes in sandbar area and volume based on annual sandbar surveys and time-lapse photographs of various sandbar monitoring sites that specifically highlight changes in sandbar characteristics associated with particular experiments. These data will be accompanied by an annual interpretative statement of the trends of sandbars that will be updated at the time of each year's annual reporting meeting. Similar data will be provided regarding humpback chub populations, rainbow trout populations and the associated fishery, the aquatic food base, and other resources of interest, as appropriate, for addressing conservation measures and triggered actions consistent with the ROD.

The LTEMP ROD calls for a comprehensive, decadal-scale assessment of the impact of dam operations on sandbar resources and on the status of humpback chub. These assessments are specifically identified in the LTEMP ROD attachment B, figures 4 (the decision tree for operational decisions concerning sediment resources) and 5 (the decision tree for operational decisions regarding aquatic resources) (U.S. Department of the Interior, 2016b). The former figure shows that an assessment will be provided that addresses the question, "Does monitoring indicate sandbar area and volume are maintained or increased in the first 10 years with no unacceptable effects on sand mass balance in Marble Canyon?” If this question is answered in the negative, as stated in the LTEMP ROD attachment $\mathrm{B}$, figure 4, then DOI should adjust operations and triggers to increase sediment conservation, and consider other actions if feasible and necessary. The LTEMP ROD attachment B, figure 5, indicates that temperature effects on humpback chub will be evaluated after 10 years to determine if additional actions or experiments are necessary. If this question is answered in the affirmative, managers will "Consider conducting low summer flow experiment, adjust operations and triggers (based on learning) or consider other actions to increase recruitment." As part of this consideration, the ROD indicates that DOI "will convene a scientific panel that includes independent experts prior to the first potential use of low summer flows to synthesize the best available scientific information related to low summer flows." In each case, if operations and non-flow actions implemented in the first 10 years are demonstrated to have the desired effects, then those activities are to continue for another decade. To implement the processes 
depicted in the LTEMP ROD attachment B, figures 4 and 5, these assessments of the effects of operations and experimental flow and non-flow actions are crucial.

Because of the importance of these assessments, GCMRC will publish each 10-year assessment as a peer-reviewed USGS report. Although management recommendations will not be made, these scientific reports will explicitly address the issues of (1) decade-scale changes in sandbar area and volume, (2) decade-long changes in sand mass balance, and (3) decade-long changes in humpback chub status in relation to water temperature. Sandbar and sand mass-balance data will be reported in the context of short-term variability, shorter segment-scale attributes of sandbars and sand mass balance, and multidecade trends in sandbar area and volume. Humpback chub data will be reported in the context of juvenile and subadult growth rates and subsequent effects on recruitment rates into subadult and adult life stages. Preliminary analysis of these data may commence as early as 2022, which is 10 years after initiation of the HFE protocol and nonnative fish control EAs, and the final report is to be issued in 2027, approximately 10 years after the start of LTEMP ROD implementation. During the period between 2022 and 2027, GCMRC intends to make annual presentations to GCDAMP stakeholders of its preliminary findings regarding these issues.

\section{Predictions of the Effects of Specific Experimental Management Actions on Resources}

The selected alternative in the ROD makes reference to predictions about the anticipating the effects of some experimental actions. Specifically,

- "Prior to implementation of any experiment, the relative effects of the experiment on ... resource areas will be evaluated and considered."

- “. . . implementation of experimental treatments would continue throughout the LTEMP period .

. . except in years when it was determined that the proposed experiment could result in unacceptable adverse impacts on resource conditions.”

The LTEMP does not provide guidance concerning the specificity of these predictions; however, the focus of these predictions in the context of LTEMP is primarily on anticipating unacceptable outcomes. Nevertheless, it is imperative that GCMRC continue to refine its predictive capacity to anticipate the outcome of future experimental actions.

For example, GCMRC scientists and collaborators have previously developed a predictive model of rainbow trout recruitment based on flow drivers (Korman and others, 2012) that was used in the development of the LTEMP and are creating an updated version of this rainbow recruitment model to explore other drivers and incorporate learning over the past 5 years. GCMRC scientists also developed a predictive model of humpback chub population dynamics in response to various drivers for the LTEMP (U.S. Department of the Interior, 2016a, appendix F) and plan to continue to refine this model and improve its predictive ability. In addition, GCMRC scientists have used a geographic information system (GIS)-based stage elevation model to predict the area within the boundaries of archaeological sites that would be inundated by a 45,000 $\mathrm{ft}^{3} / \mathrm{s}\left(1,274 \mathrm{~m}^{3} / \mathrm{s}\right) \mathrm{HFE}$, which was useful for refining our understanding of potential direct impacts to sites from future flow events (Sondossi and Fairley 2014).

\section{Time Frame for Data Collection and Reporting Required to Implement the Selected Alternative of the LTEMP ROD}

GCMRC is to provide data and analysis so that the GCDAMP can advise and DOI can implement various decisions and actions of the selected alternative of the LTEMP ROD. Specifically: 
1. Before any action or experiment, data sufficient for resource "evaluation and consideration" is to be provided by data served on the GCMRC Web site, briefings to the TWG, and briefings to DOI agencies,

2. Monthly, GCMRC is to provide data as needed during Bureau of Reclamation dam operations conference calls,

3. During the spring and fall sediment accounting periods, fine sediment input data is to be provided on the GCMRC Web site, and these data will be available to all stakeholders,

4. Annually, GCMRC is to provide requested data to the Bureau of Reclamation in support of development of the annual hydrograph,

5. Annually, GCMRC is to provide data, analysis, and long-term status of key resources reports at its annual reporting meeting (this meeting is held in conjunction with the January TWG meeting and is open to the public),

6. After sufficient testing, GCMRC is to provide an evaluation of TMFs (this report will be provided as a USGS peer-reviewed report),

7. GCMRC is to provide data necessary to support other aspects of decisions regarding implementation of spring HFEs and of proactive spring HFEs, which will not be implemented during the first 2 years of the LTEMP period,

8. GCMRC is to provide data necessary to design experiments and data collection related to macroinvertebrate production flows,

9. After a decade, GCMRC is to evaluate changes in the status of humpback chub populations in relation to river temperature (this report will be provided as a USGS peer-reviewed report), and

10. After a decade, GCMRC is to evaluate changes in sandbar area and volume and distinguish the role of dam operations in causing those changes (this report will be provided as a USGS peerreviewed report).

\section{References}

Alvarez, L.V. and Schmeeckle, M.W., 2013, Erosion of river sandbars by diurnal stage fluctuations in the Colorado River in the Marble and Grand Canyons—Full-scale laboratory experiments: River Research and Applications, v. 29, no. 7, p. 839-854, accessed on January 17, 2017, at http://dx.doi.org/10.1002/rra.2576.

Bureau of Reclamation, National Park Service, U.S. Geological Survey, U.S. Fish and Wildlife Service, Arizona Game and Fish Department, and private consultants, 1988, Glen Canyon Environmental Studies final report: Salt Lake City, Utah, submitted to the Department of the Interior, Bureau of Reclamation, Upper Colorado Regional Office, revised and reprinted May 1989, 84 p. plus appendixes, accessed on January 13, 2017, at https://www.gcmrc.gov/library/reports/GCES/GCES1989.pdf.

Bureau of Reclamation, 2011a, Environmental assessment-Development and implementation of a protocol for high-flow experimental releases from Glen Canyon Dam, Arizona, 2011through 2020: Salt Lake City, Utah, Bureau of Reclamation, Upper Colorado Region, 176 p. plus appendixes, accessed on January 13, 2017, at http://www.usbr.gov/uc/envdocs/ea/gc/HFEProtocol/HFE-EA.pdf.

Bureau of Reclamation, 2011b, Environmental assessment-Non-native fish control downstream from Glen Canyon Dam: Salt Lake City, Utah, Bureau of Reclamation, Upper Colorado Region, 102 p. plus appendixes, accessed on January 13, 2017, at http://www.usbr.gov/uc/envdocs/ea/gc/nnfc/NNFCEA.pdf.

Bureau of Reclamation and U.S. Geological Survey, 2014, Glen Canyon Adaptive Management Program triennial budget and work plan-Fiscal years 2015-2017: Bureau of Reclamation, Upper Colorado Regional Office, and U.S. Geological Survey, Grand Canyon Monitoring and Research 
Center, prepared in conjunction with the Glen Canyon Dam Adaptive Management Program, 536 p., accessed on January 13, 2017, at

https://www.usbr.gov/uc/rm/amp/amwg/mtgs/14aug27/Attach_06f.pdf.https://www.usbr.gov/uc/rm/a mp/amwg/mtgs/14aug27/Attach_06f.pdf.

Gloss, S.P., and Coggins, L.G., 2005, Fishes of the Grand Canyon, in Gloss, S.P., Lovich, J.E., and Melis, T.S., eds., The state of the Colorado River ecosystem in Grand Canyon-A report of the Grand Canyon Monitoring and Research Center 1991-2004: U.S. Geological Survey Circular 1282, 33-56 p., accessed on January 13, 2017, at https://pubs.usgs.gov/circ/1282/.

Grams, P.E., Topping, D.J., Schmidt, J.C., Hazel, J.E., Jr., and Kaplinski, M.A., 2013, Linking morphodynamic response with sediment mass balance on the Colorado River in Marble CanyonIssues of scale, geomorphic setting, and sampling design: Journal of Geophysical Research-Earth Surface, v. 118, no. 2, p. 361-381, accessed January 13, 2017, at http://dx.doi.org/10.1002/jgrf.20050. Grams, P.E., Buscombe, D., Topping, D.J., Hazel, J.E.J., and Kaplinski, M., 2015, Use of flux and morphologic sediment budgets for sandbar monitoring on the Colorado River in Marble Canyon, Arizona: Proceedings of the 5th Federal Interagency Hydrologic Modeling Conference and the 10th Federal Interagency Sedimentation Conference, p. 1144-1155, accessed January 13, 2017, at https://acwi.gov/sos/pubs/3rdJFIC/Proceedings.pdf.

Grams, P.E., Schmidt, J.C., Wright, S.A., Topping, D.J., Melis, T.S., and Rubin, D.M., 2015, Building sandbars in the Grand Canyon: EOS, Transactions, American Geophysical Union, v. 96, no. 11, p. 12-16, accessed January 13, 2017, at https://eos.org/features/building-sandbars-in-the-grand-canyon. Hazel, J.E., Jr., Grams, P.E., Schmidt, J.C., and Kaplinski, M., 2010, Sandbar response in Marble and Grand Canyons, Arizona, following the 2008 high-flow experiment on the Colorado River: U.S. Geological Survey Scientific Investigations Report 2010-5015, 52 p., accessed January 13, 2017, at https://pubs.usgs.gov/sir/2010/5015/.

Kennedy, T.A., Muehlbauer, J.D., Yackulic, C.B., Lytle, D.A., Miller, S.W., Dibble, K.L., Kortenhoeven, E.W., Metcalfe, A.N., and Baxter, C.V., 2016, Flow management for hydropower extirpates aquatic insects, undermining river food webs: BioScience, v. 66, no. 7, p. 561-575, accessed January 17, 2017, at http://dx.doi.org/10.1093/biosci/biw059.

Kennedy, T.A., and Gloss, S.P., 2005, Aquatic ecology-The role of organic matter and invertebrates, in Gloss, S.P., Lovich, J.E., and Melis, T.S., eds., The state of the Colorado River ecosystem in Grand Canyon-A report of the Grand Canyon Monitoring and Research Center 1991-2004: U.S. Geological Survey Circular 1282, 87-101 p., accessed January 17, 2017, at https://pubs.usgs.gov/circ/1282/.

Korman, J., Martell, S.J.D., Walters, C.J., Makinster, A.S., Coggins, L.G., Yard, M.D., and Persons, W.R., 2012, Estimating recruitment dynamics and movement of rainbow trout (Oncorhynchus mykiss) in the Colorado River in Grand Canyon using an integrated assessment model: Canadian Journal of Fisheries and Aquatic Sciences, v. 69, no. 11, p. 1827-1849, accessed January 13, 2017, at http://dx.doi.org/10.1139/F2012-097.

Melis, T.S., ed., 2011, Effects of three high-flow experiments on the Colorado River ecosystem downstream from Glen Canyon Dam, Arizona: U.S. Geological Survey Circular 1366, 147 p., accessed January 13, 2017, at https://pubs.usgs.gov/circ/1366/.

Minckley, W.L., 1991, Native fishes of the Grand Canyon region-An obituary?, in National Research Council, Committee to Review the Glen Canyon Environmental Studies, Water Science and Technology Board, Colorado River Ecology and Dam Management_-Proceedings of a Symposium May 24-25, 1990, Santa Fe, New Mexico: Washington, D.C., National Academy Press, p. 124-177, accessed January 17, 2017, at https://www.nap.edu/read/1832/chapter/9. 
National Park Service, 2013, Comprehensive Fisheries Management Plan for Grand Canyon National Park and Glen Canyon National Recreation Area, Environmental Assessment and Finding of No Significant Impact: U.S. Department of Interior, Intermountain Region-National Park Service, Lakewood, Colorado, accessed January 17, 2017, at https://parkplanning.nps.gov/documentsList.cfm?projectID=35150.

Rubin, D.M., Topping, D.J., Schmidt, J.C., Hazel, J.E., Kaplinski, M., and Melis, T.S., 2002, Recent sediment studies refute Glen Canyon Dam hypothesis: EOS, Transactions, American Geophysical Union, v. 83, p. 273.

Schmidt, J.C., and Graf, J.B., 1990, Aggradation and degradation of alluvial sand deposits, 1965 to 1986, Colorado River, Grand Canyon National Park, Arizona: U.S. Geological Survey Professional Paper 1493, 74 p., accessed January 17, 2017, at https://pubs.er.usgs.gov/usgspubs/pp/pp1493.

Schmidt, J.C., Webb, R.H., Valdez, R.A., Marzolf, G.R., and Stevens, L.E., 1998, Science and values in river restoration in the Grand Canyon: BioScience, v. 48, no. 9, p. 735-747.

Sondossi, H.A., and Fairley, H.C., 2014, An analysis of the potential for Glen Canyon Dam releases to inundate archaeological sites in the Grand Canyon, Arizona: U.S. Geological Survey Open-File Report 2014-1193, 26 p., accessed January 13, 2017, at https://dx.doi.org/10.3133/ofr20141193.

Topping, D.J., Rubin, D.M., Nelson, J.M., Kinzell, P.J., and Corson, I.C., 2000a, Colorado River sediment transport 2-Systematic bed-elevation and grain-size effects of sand supply limitation: Water Resources Research, v. 36, p. 543-570.

Topping, D.J., Rubin, D.M., and Vierra, L.E.J., 2000b, Colorado River sediment transport 1—Natural sediment supply limitation and the influence of Glen Canyon Dam: Water Resources Research, v. 36, p. 515-542.

Topping, D.J., Schmidt, J.C., and Vierra, L.E., 2003, Computation and analysis of the instantaneousdischarge record for the Colorado River at Lees Ferry, Arizona-May 8, 1921, through September 30, 2000: U.S. Geological Survey Professional Paper 1677, 118 p., accessed January 17, 2017, at https://pubs.usgs.gov/pp/pp1677/.

U.S. Department of the Interior, 1988, Glen Canyon environmental studies final report: Bureau of Reclamation, Salt Lake City, Utah, revised and reprinted May 1989.

U.S. Department of the Interior, 2012, Desired future conditions for the Colorado River Ecosystem in relation to Glen Canyon Dam: U.S. Department of the Interior report and supporting memorandums, accessed January 17, 2017, at https://www.usbr.gov/uc/rm/amp/amwg/pdfs/recltr_12April30.pdf.

U.S. Department of the Interior, 2016a, Glen Canyon Dam Long-Term Experimental and Management Plan Final Environmental Impact Statement: U.S. Department of the Interior, Bureau of Reclamation, Salt Lake City, Utah, and National Park Service, Lakewood, Colorado, accessed January 13, 2017, at http://tempeis.anl.gov/documents/.

U.S. Department of the Interior, 2016b, Record of Decision for the Glen Canyon Dam Long-Term Experimental and Management Plan Final Environmental Impact Statement: U.S. Department of the Interior, Bureau of Reclamation, Salt Lake City, Utah, and National Park Service, Lakewood, Colorado, accessed January 13, 2017, at http://ltempeis.anl.gov/documents/.

Valdez, R.A., and Ryel, R.J., 1995, Life history and ecology of the humpback chub (Gila cypha) in the Colorado River, Grand Canyon, Arizona: BIO/WEST report no. TR-250-08, final report to the Bureau of Reclamation, Salt Lake City, Utah.

Vernieu, W.S., Hueftle, S.J., and Gloss, S.P., 2005, Water quality in Lake Powell and the Colorado River, in Gloss, S.P., Lovich, J.E., and Melis, T.S., eds., The state of the Colorado River ecosystem in Grand Canyon-A report of the Grand Canyon Monitoring and Research Center 1991-2004: U.S. Geological Survey Circular 1282, p. 69-85, accessed January 13, 2017, at https://pubs.usgs.gov/circ/1282/. 
Webb, R.H., Schmidt, J.C., Marzolf, G.R., and Valdez, R.A., 1999, The controlled flood in Grand Canyon: Washington, D.C., American Geophysical Union, Geophysical Monograph Series, v. 110, $367 \mathrm{p}$.

Winters, L.K., Rogowoski, D.L., and Wolters, P. H., 2016, Status of the Lees Ferry rainbow trout fishery, 2015: Annual Report to the USGS Grand Canyon Monitoring and Research Center, Flagstaff, Arizona, 47 p.

Yard, M.D., Coggins, L.G., Jr., Baxter, C.V., Bennett, G.E., and Korman, J., 2011, Trout piscivory in the Colorado River, Grand Canyon-Effects of turbidity, temperature, and fish prey availability:

Transactions of the American Fisheries Society, v. 140, no. 2, p. 471-486, accessed January 17, 2017, at http://dx.doi.org/10.1080/00028487.2011.572011. 
ISSN 2331-1258 (online)

https://doi.org/10.3133/ofr20171006 